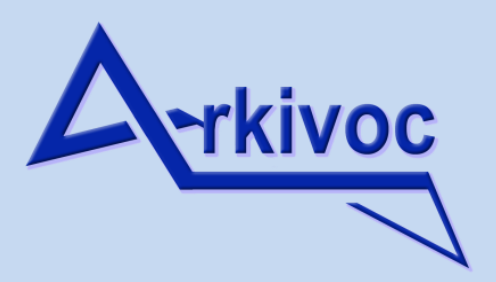

Archive for

Organic Chemistry
The Free Internet Journal

for Organic Chemistry
Paper

Arkivoc 2020, part ii, 61-76

\title{
Substitution by tert-butyl groups facilitates excited state proton transfer in hydroxylated triphenylimidazole frameworks more than it does for oxazole and thiazole analogs
}

Fabricio de Carvalho, Mauricio D. Coutinho-Neto, Fernando H. Bartoloni,* and Paula Homem-de-Mello*

Centro de Ciências Naturais e Humanas, Universidade Federal do ABC, Santo André/SP, Brazil

Email: fernando.bartoloni@ufabc.edu.br; paula.mello@ufabc.edu.br

Dedicated to Professor José Manuel Riveros

Received 11-15-2019

Accepted 02-07-2020

Published on line $02-19-2020$

\section{Abstract}

Excited state intramolecular proton transfer (ESIPT) processes typically occur when photoexcited molecules relax via a tautomeric proton transfer event in the excited state, and it is known to depend on the properties of donor and acceptor groups. In this work, we employed ground state and Time Dependent Density Functional Theory aiming at studying the ESIPT viability on triphenyl-substituted heterocyclic (imidazole, oxazole, and thiazole) tert-butyl derivatives. For all compounds, the formation of a keto tautomer is favored once an excited state is generated from a ground state enol tautomer. The expected tert-butyl electron donor effect and enol form stabilization is verified in the ground state, but the opposite is observed for the excited state. We found that tert-butyl substituted compounds have reduced HOMO-LUMO gap, exhibit barrierless proton transfer in the excited state and stronger Hydrogen bond after light excitation.

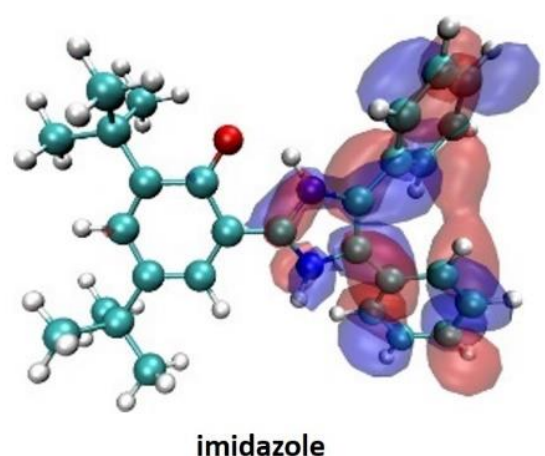

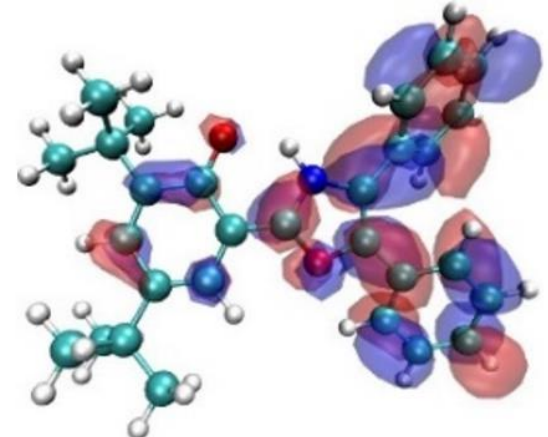

oxazole

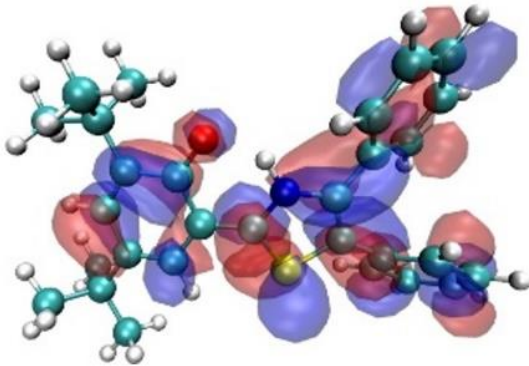

thiazole

Keywords: ESIPT, imidazole, oxazole, thiazole, tert-butyl groups, DFT 


\section{Introduction}

Excited State Intramolecular Proton Transfer (ESIPT) is a phenomenon where the established equilibrium between tautomers is perturbed upon the formation of excited states (Scheme 1). ${ }^{1,2}$ Usually, enol and ketolike tautomers are involved. At the same time, the first is the most stable species on the electronic singlet ground state $\left(S_{0}\right)$. When the enol absorbs a photon and reaches the electronic singlet excited state $\left(S_{1}\right)$, a proton $\left(\mathrm{H}^{+}\right)$is transferred from a donor site to an acceptor group within the molecular framework, generating the other tautomer in its $S_{1}$ state accompanied by an overall decrease in energy. Fluorescence emission ensues from the keto $\mathrm{S}_{1}$ to its $\mathrm{S}_{0}$, and a ground state $\mathrm{H}^{+}$transfer reestablishes the distribution of tautomers before photoexcitation. Since there is a significant difference in energies concerning absorption and emission by different tautomers, Stokes shift larger than $8000 \mathrm{~cm}^{-1}$ are commonly observed in ESIPT operating systems. Excited-state formation leads to the simultaneous increase in acidity and basicity of the groups involved with $\mathrm{H}^{+}$movement (i.e., photoacidity/basicity). Thus, proton transfer and formation of the $\mathrm{S}_{1}$ keto tautomer occurs on the timescale of photochemical processes. ${ }^{1,2}$ This results, for example, in fluorescence quenching of the enol tautomer ${ }^{3}$ and the possibility of off-on emission response under different conditions. ${ }^{5}$

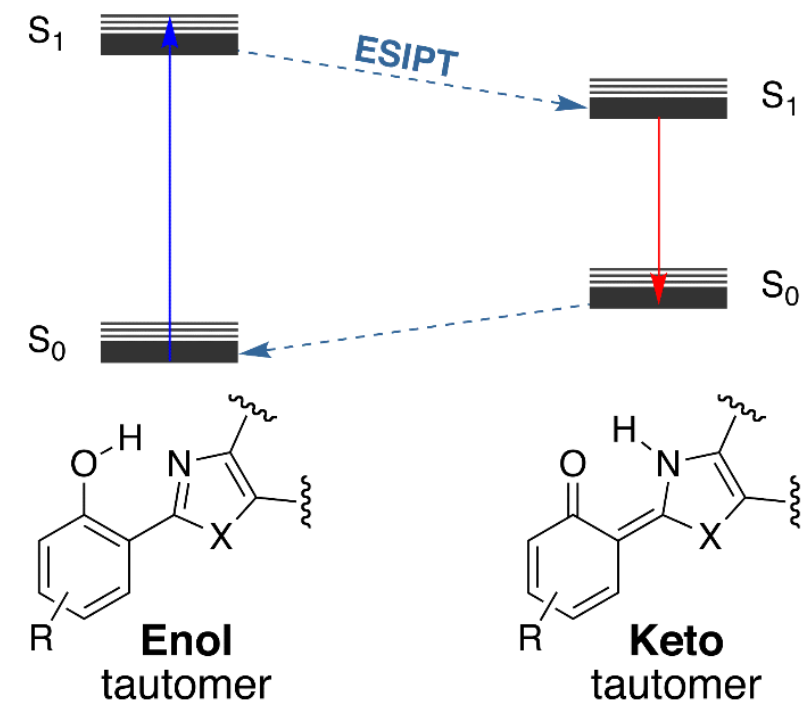

Scheme 1. Excited state intramolecular proton transfer (ESIPT) mechanism.

Changing $\mathrm{H}^{+}$donor and acceptor groups within the molecule or its substitution patterns, as well as environment features (i.e., changes in solvent or addition of ions) can modulate the distribution of species in the excited state, therefore, altering the registered fluorescence profile. ${ }^{3,6-10}$ Since the dynamics of this phototautomerization is so sensitive to structural and environmental aspects, ESIPT acts as the underlying basis of a wide range of applications, such as laser dyes, solar energy condensers, chemosensors and fluorosensors, luminescent and electroluminescent materials, photostabilizers, molecular probes, optoelectronic devices, among others. ${ }^{9-17}$ Such a broad exploration of ESIPT in applications depends on rationalizing the phenomenon on an experimental level and, equally important, through computational simulation techniques. ${ }^{7,18-24}$

In the process of understanding ESIPT, some studies were carried out to compare the properties of different benzazole derivatives (i.e., benzimidazole, benzoxazole, etc.) as proton acceptors, using appended phenols as donors. ${ }^{7,25}$ Triphenylimidazoles are compounds with high fluorescence quantum yield $\left(\Phi_{\mathrm{FL}}>40 \%\right)^{26}$ 
and, since light emission efficiency is a key factor, these have been used successfully for the detection of metallic cations due to the formation of coordinated compounds that perturb ESIPT. ${ }^{3,10}$ In a previous work, we have explored the dynamics of ESIPT in three different hydroxylated triphenylazoles (1a-3a) using DFT, and TD-DFT calculations. ${ }^{27}$ With these compounds, intramolecular proton transfer in the electronic fundamental state must overcome a $>10 \mathrm{kcal} \mathrm{mol}^{-1}$ energy barrier, which becomes $<1 \mathrm{kcal} \mathrm{mol}^{-1}$ in the excited state. The identity of the heterocyclic functionality is also relevant, with the HOMO-LUMO transition energy gap increasing in the sequence thiazole, oxazole, imidazole; interestingly, the smaller emission energy was observed for the imidazole derivative. ${ }^{27}$

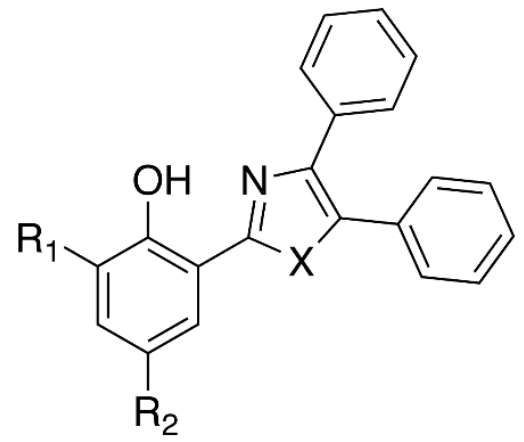

$$
\begin{aligned}
& X=N H(1), O(2), S(3) \\
& \mathrm{R}_{1}=\mathrm{R}_{2}=\mathrm{H}(\mathrm{a}) \\
& \mathrm{R}_{1}=t \text {-butyl, } \mathrm{R}_{2}=\mathrm{H}(\mathrm{b}) \\
& \mathrm{R}_{1}=\mathrm{H}, \mathrm{R}_{2}=t \text {-butyl (c) } \\
& \mathrm{R}_{1}=\mathrm{R}_{2}=t \text {-butyl (d) }
\end{aligned}
$$

Figure 1. Molecular structure of the studied compounds (data for compounds $1 \mathbf{a}, \mathbf{2 a}$ and $\mathbf{3 a}$ have been published before ${ }^{27}$ and are reported in this work only for comparison purposes).

Geometry reorganization is extremely significant for $\mathrm{ESIPT}^{28}$, and so must be the presence of additional vibrational modes for excited-state deactivation. The presence of tert-butyl groups as substituents in hydroxylated triphenylazoles (1)-d, $\mathbf{2} \mathbf{b}-\mathbf{d}$ and $\mathbf{3 b}-\mathbf{d}$ ) may be of importance for the dynamics of proton transfer. Experimentally, it has been observed that the free rotor effect attributed to tert-butyl groups in part reduces $\Phi_{\mathrm{FL}}$ from $35 \%$ to $1.3 \%$ when comparing $1 \mathbf{a}^{3}$ with $\mathbf{1} \mathbf{d}^{10}$. Tert-butyl groups are commonly applied in organic systems were proton-coupled electron transfer operates, to avoid self-quenching of the electrochemically generated radical. ${ }^{29-32}$ Therefore, in this work we use DFT and TD-DFT calculations for hydroxylated triphenylazoles 1-3, mainly to rationalize the role of tert-butyl substitution on the context of ESIPT.

\section{Results and Discussion}

\section{Ground state conformations}

Initially, it is crucial to characterize the ground state conformations and the stability of closed, open and rotamer conformers of 1-3 (Figure 2). Ground state conformations are relevant for the overall rationalization of ESIPT systems. ${ }^{4,27,33}$ Geometries and structure parameters are displayed in Supplementary Material (Figures SM2 to SM4, Tables SM1 to SM3) and Table 1 presents the relative energies of open and rotamer forms with the closed form as reference. Closed conformers, as expected, are more stable in the ground state due the intramolecular hydrogen bonding between hydroxyl and the $s p^{2}$ nitrogen of azole groups. Moreover, for all the calculated closed forms, the preferential tautomer in the ground state was the enol. 


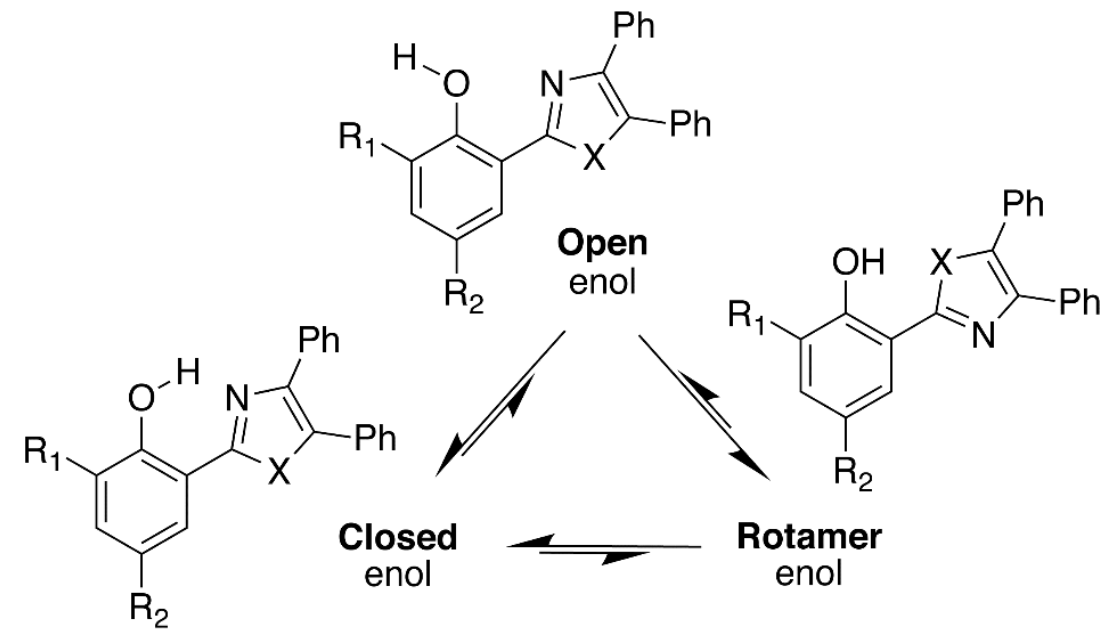

Figure 2. Possible closed, open and rotamer conformations for the hydroxylated triphenylazoles 1-3 studied in this work.

Table 1. Relative energies with the closed conformer (C) as reference, in $\mathrm{kcal} \mathrm{mol}^{-1}$, for the electronic ground state of 1-3 in the open $(\mathrm{O})$ and rotamer $(\mathrm{R})$ conformers

\begin{tabular}{ccc}
\hline Compound & $\Delta \mathrm{E}_{\mathrm{O}-\mathrm{c}} / \mathrm{kcal} \mathrm{mol}^{-1}$ & $\Delta \mathrm{E}_{\mathrm{R}-\mathrm{C}} / \mathrm{kcal} \mathrm{mol}^{-1}$ \\
\hline 1a* & 13.55 & 8.47 \\
1b & 13.87 & 9.76 \\
1c & 9.79 & 8.18 \\
1d & 11.48 & 9.57 \\
2a* & 12.55 & 5.77 \\
2b & 12.72 & 5.71 \\
2c & 11.49 & 6.21 \\
2d & 13.56 & 4.96 \\
3a* & 12.68 & 9.48 \\
3b & 14.04 & 12.10 \\
3c & 11.98 & 8.76 \\
3d & 12.80 & 8.20 \\
\hline
\end{tabular}

* data have been published before ${ }^{27}$ and are reported in this work only for comparison purposes.

The energy difference between closed and open forms $\left(\Delta \mathrm{E}_{\mathrm{O}-\mathrm{c}}\right.$, Table 1$)$ can be approximated to the hydrogen bond strength of these systems, with more positive values representing stronger intramolecular interactions. The a-type compounds (i.e., without tert-butyl substituents), are presented here for comparison purposes, aiming to evaluate the influence of the alkyl groups on the overall properties of the molecules. The average hydrogen bond strength is about $12.5 \mathrm{kcal} \mathrm{mol}^{-1}$ and ortho-substituted compounds (b-type) have this interaction slightly increased. This should be related to the steric influence of the alky group that prevents $\mathrm{C}-\mathrm{O}$ bond rotation to generate the open form, thus, increasing the energy difference between conformers. On the other hand, para substitutions (c-type) induce weaker hydrogen bonds, particularly for the imidazole derivative (1c). Probably, the electron-donating inductive effect of the alkyl group, specifically at the para 
position, is diminishing the acidity of the phenol and preventing the generation of charges and donation of the proton to the basic site. When two tert-butyl substituents are present (d-type) the strength of this intramolecular interaction increases again, in a more significant way for oxazole compound (2d). For $\mathbf{1 d}$ and $3 d$, it can be seen that $\Delta \mathrm{E}_{\mathrm{O}-\mathrm{c}}$ values represent a combination of the opposing steric and electronic effects of the substituents (Table 1 ).

Rotamer energies are always smaller than that obtained for open conformers since a new hydrogen bond between the phenol group and the $s p^{3}$ heteroatom of the heterocyclic is allowed; this is particularly relevant for the oxazoles $\mathbf{2 a - d}$. For the imidazole, 1a-d, and thiazole derivatives, 3a-d, this hydrogen bond is not effective, since the acceptor is a $s p^{3}$ nitrogen atom, in the first case, or a sulfur atom, for the latter, as discussed elsewhere. ${ }^{27}$

\section{Absorption spectra}

The absorption spectra for the compounds presented here are composed of two main transitions in the region between 350 and $300 \mathrm{~nm}$ (Table 2). The first one, with a smaller associated energy, corresponds to a HOMOLUMO transition while the latter to a HOMO-LUMO+1 transition. The first transition is maintained as HOMOLUMO for all the derivatives, but tendencies on energy variation are not the same for the different heterocycles. Regarding the second transition, it is maintained as HOMO-LUMO+1 for the substituted compounds, except for the substituted derivatives of oxazole $\mathbf{2} \mathbf{b}-\mathbf{d}$ for which the second transition is degenerated with the HOMO-1-LUMO transition. Also, for this transition, there is no observed tendency with the substitution.

The molecular orbitals energy diagram (Figure 2) shows that the tert-butyl substitution opens the gap for imidazole compounds, especially when in para position (1c), because the substitution increases the energy of the LUMO. However, the effect on oxazole (2b-d) and thiazole (3b-d) is mainly observed on HOMO, destabilizing this orbital, so that the gap becomes smaller when compared to the non-substituted compound (2a and 3a). For $\mathbf{2 d}$ and $\mathbf{3 d}$ (i.e., compounds with two tert-butyl substituents), both HOMO and LUMO are destabilized, but the energy gap for $\mathbf{3} \mathbf{d}$ is not affected while the one for $\mathbf{2} \mathbf{d}$ increases. Overall, it could be said that comparing the a-type compounds with the b-type, it is observed that substitution in ortho has little to no effect on the energy of frontier orbitals, emphasizing the hypothesis that in this configuration the tert-butyl group has more steric influence than electronic. In agreement with this observation, c-type compounds show that substitution in para has more effect over HOMO and LUMO energies, according to the electronic nature of its influence. 
Table 2. Electronic absorption spectra data obtained for all the compounds studied. Wavelength of absorption $\left(\lambda_{\mathrm{Abs}}\right.$ in $\left.\mathrm{nm}\right)$, oscillator strength $(\mathrm{f})$ and main molecular orbitals $(\mathrm{MO})$ involved in the transition

\begin{tabular}{|c|c|c|c|}
\hline compounds & $\lambda_{\text {Abs. }} / \mathrm{nm}$ & $f$ & $\mathrm{MO} / \%$ \\
\hline \multirow{2}{*}{$1 a^{*}$} & 338 & 0.385 & HOMO-LUMO/94 \\
\hline & 311 & 0.429 & HOMO-LUMO+1/87 \\
\hline \multirow{2}{*}{ 1b } & 337 & 0.373 & HOMO-LUMO/95 \\
\hline & 310 & 0.386 & HOMO-LUMO+1/70 \\
\hline \multirow{2}{*}{ 1c } & 327 & 0.396 & HOMO-LUMO/95 \\
\hline & 300 & 0.410 & HOMO-LUMO+1/90 \\
\hline \multirow{2}{*}{ 1d } & 331 & 0.373 & HOMO-LUMO/95 \\
\hline & 302 & 0.457 & HOMO-LUMO+1/92 \\
\hline \multirow{3}{*}{$2 a^{*}$} & 339 & 0.672 & HOMO-LUMO/94 \\
\hline & 305 & 0.227 & HOMO-LUMO+1/78 \\
\hline & 343 & 0.578 & HOMO-LUMO/93 \\
\hline \multirow[t]{3}{*}{$2 b$} & 310 & 0.105 & HOMO-1-LUMO/82 \\
\hline & 306 & 0.281 & HOMO-LUMO+1/82 \\
\hline & 349 & 0.510 & HOMO-LUMO/93 \\
\hline \multirow[t]{3}{*}{ 2c } & 312 & 0.247 & HOMO-LUMO+1/47 \\
\hline & 307 & 0.175 & HOMO-1-LUMO/44 \\
\hline & 335 & 0.542 & HOMO-LUMO/90 \\
\hline \multirow[t]{2}{*}{$2 d$} & 302 & 0.247 & HOMO-1-LUMO/84 \\
\hline & 297 & 0.198 & HOMO-LUMO+1/86 \\
\hline \multirow{2}{*}{$3 a^{*}$} & 346 & 0.548 & HOMO-LUMO/94 \\
\hline & 303 & 0.119 & HOMO-LUMO+1/86 \\
\hline \multirow{2}{*}{$3 b$} & 346 & 0.462 & HOMO-LUMO/91 \\
\hline & 310 & 0.131 & HOMO-LUMO+1/90 \\
\hline \multirow{2}{*}{$3 c$} & 358 & 0.490 & HOMO-LUMO/93 \\
\hline & 309 & 0.146 & HOMO-LUMO+1/85 \\
\hline \multirow{2}{*}{$3 d$} & 351 & 0.416 & HOMO-LUMO/92 \\
\hline & 304 & 0.135 & HOMO-LUMO+1/91 \\
\hline
\end{tabular}

* data have been published before ${ }^{27}$ and are reported in this work only for comparison purposes 


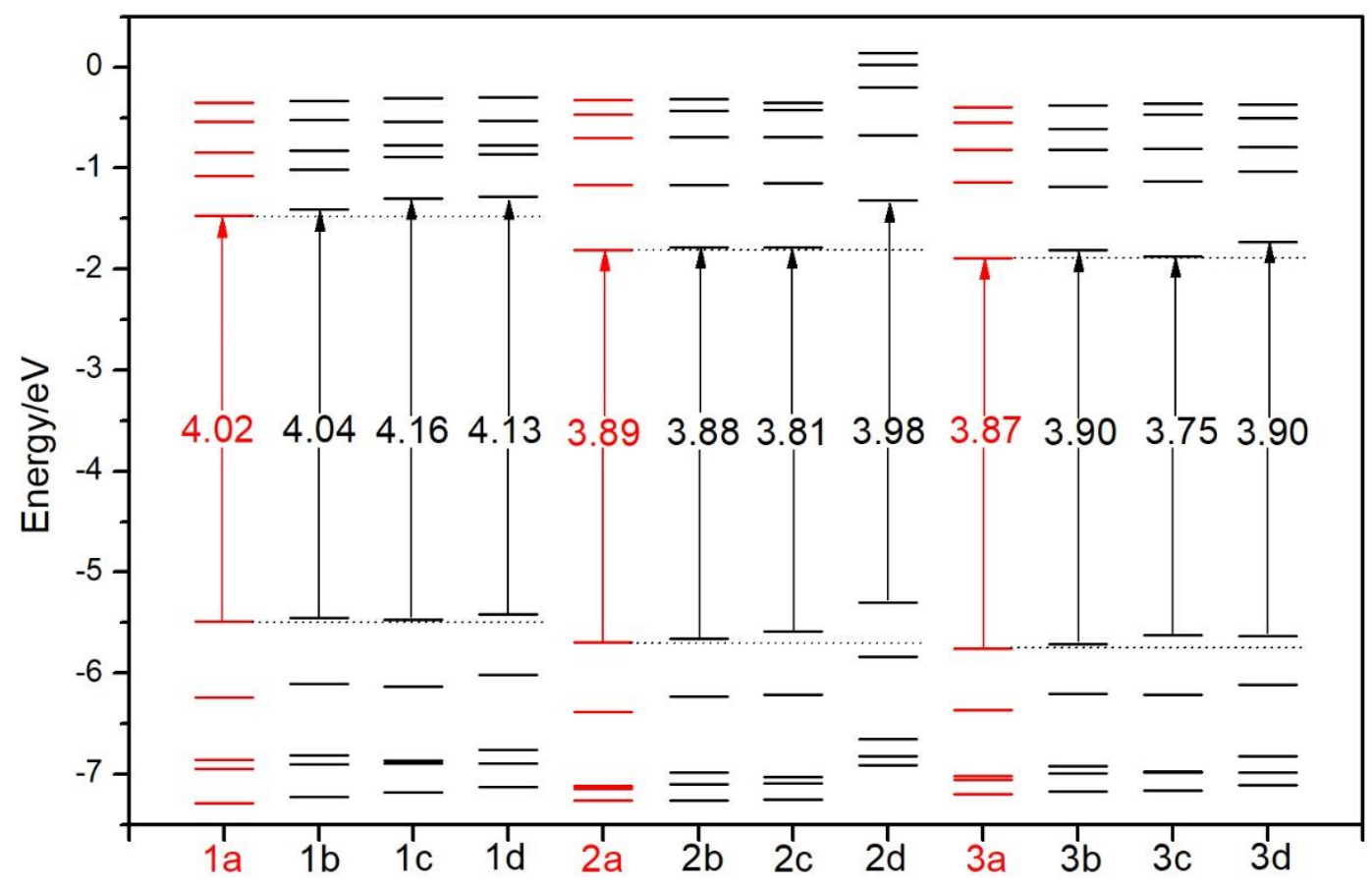

Figure 2. Diagrams of molecular orbital energies for the compounds studied.

To better rationalize the effect of tert-butyl substitution on molecular orbitals energy, it is important to verify their spatial distribution (Figures SM7, SM11, and SM15 for enol/closed conformers). For 2a-d and 3a-d derivatives, HOMO and HOMO-1 have contributions of the whole conjugated system, while for 1a-d only the HOMO has this characteristic. For LUMO and LUMO+1, the electronic density remains distributed over the conjugated part of the molecule. It is interesting to note that tert-butyl groups do not contribute to virtual orbitals but contributes to HOMO-1, and only para substitution has a small contribution to HOMO. Changes in molecular orbitals energy and on molecular maps are subtle, but it is possible to observe a decrease in density in the phenyl rings caused by para substitution, affecting HOMO and LUMO for $c$-derivatives, but mainly for $d$ type compounds.

Besides that, molecular orbitals density can give some insight into excited states. ${ }^{34}$ The electron density analysis of compounds supports the existence of the proton transfer process in the excited state: HOMO of the enol tautomer predicts that the cyclic system formed by the intramolecular hydrogen bond has a binding character on hydroxyl oxygen and the $s p^{2}$ nitrogen of the heterocycles, with a high electron density on hydroxyl oxygen.

After the HOMO-LUMO transition of the enol tautomer, a decrease in the electron density in the hydroxyl oxygen atom is observed, which should directly influence the intramolecular hydrogen bonding. Then, the next step to evaluate the proton transfer is obtaining molecular orbitals for the keto tautomer (Figures SM8, SM12 and SM16). In this case, the geometries were optimized, but the $\mathrm{N}-\mathrm{H}$ bond distance has been frozen because, as we have pointed out before, full optimizations conducted only to the enol tautomer. After tautomerization, LUMO for the ketone tautomer shows high electron density over the nitrogen atom and small electron density over the carbonyl oxygen atom; in fact, for $\mathbf{1 a - d}$ compounds there is no density at all over this oxygen atoms. When analyzing the ketone tautomer HOMO, a binding character and large electron 
density are observed over the phenolic ring, especially involving atoms $-\mathrm{OH} \cdots \mathrm{N}-$. These favor the return of the proton to the carbonyl oxygen atom, leading to the more stable ground state enol tautomer.

Table 3. Atomic charges on phenyl oxygen $(\mathrm{O})$ and on the nitrogen atom $(\mathrm{N})$ of the heterocycles, derived from the electrostatic potential using ChelpG scheme for all the studied compounds in ground state, and charge difference $(\Delta \mathrm{q})$ between $\mathrm{O}$ and $\mathrm{N}$

\begin{tabular}{ccccccc}
\hline & \multicolumn{3}{c}{ Enol } & & \multicolumn{3}{c}{ Keto } \\
\cline { 2 - 7 } 1a* & $\mathrm{N}$ & $\mathrm{O}$ & $\Delta \mathrm{q}$ & $\mathrm{N}$ & $\mathrm{O}$ & $\Delta \mathrm{q}$ \\
\cline { 2 - 7 } 1b & -0.42 & -0.51 & 0.09 & -0.21 & -0.61 & 0.40 \\
1c & -0.52 & -0.47 & 0.05 & -0.21 & -0.60 & 0.39 \\
1d & -0.47 & -0.47 & 0.00 & -0.27 & -0.60 & 0.33 \\
2a* & -0.43 & -0.50 & 0.07 & -0.26 & -0.60 & 0.34 \\
2b & -0.41 & -0.45 & 0.04 & -0.26 & -0.57 & 0.32 \\
2c & -0.42 & -0.49 & 0.07 & -0.29 & -0.60 & 0.34 \\
2d & -0.48 & -0.46 & -0.02 & -0.31 & -0.60 & 0.31 \\
3a* & -0.33 & -0.49 & 0.16 & -0.17 & -0.58 & 0.41 \\
3b & -0.33 & -0.45 & 0.12 & -0.15 & -0.56 & 0.41 \\
3c & -0.34 & -0.49 & 0.15 & -0.18 & -0.58 & 0.40 \\
3d & -0.47 & -0.42 & -0.05 & -0.20 & -0.57 & 0.37 \\
\hline
\end{tabular}

* data have been published before ${ }^{27}$ and are reported in this work only for comparison purposes

As we have observed before ${ }^{27}$, atomic charges (Table 3 ) show that both the enolic and ketonic species present phenyl oxygen with a more negative charge than the nitrogen atom owned by all heterocycles. This contributes for a higher stability of the enol tautomer at the ground state when compared to the corresponding keto species. By adding tert-butyl substituents, especially in para position, charge differences tend to decrease, because tert-butyl injects charge on the conjugated system and $\mathrm{N}$ becomes more negative. This charge injection may also be responsible for the HOMO and HOMO-1 difference observed before.

\section{Excited state study}

To deepen the study of excited states, enol geometries were optimized also in the excited $\left(\mathrm{S}_{1}\right)$ state. Structural properties regarding the hydrogen bond are presented in Table 4, and other bond lengths and angles presented in Tables SM4 to SM6. For all compounds 1-3, $\mathrm{O}-\mathrm{H}$ bond length increases at the excited state and the distance of intramolecular hydrogen bond $-\mathrm{H} \cdots \mathrm{N}$ - decreases. Moreover, the angle $-\mathrm{O}-\mathrm{H} \cdots \mathrm{N}-$ increases after photoexcitation. According to Hao and $\mathrm{Yang}^{34}$, the increase in the bonding angle of the atoms involved in intramolecular hydrogen bonding in the $S_{1}$ state relative to $S_{0}$ indicates that intramolecular hydrogen bonding has been strengthened. That is, the formation of the intramolecular hydrogen bond $(-\mathrm{H} \cdots \mathrm{N}-)$ and the decrease of the covalent character of the bond $(\mathrm{O}-\mathrm{H})$ throughout the $-\mathrm{OH} \cdots \mathrm{N}$ system favors the occurrence of ESIPT. $^{34,35}$ The para-tert-butyl group increases the difference between ground and excited states, that is, hydrogen bond is strengthened in the excited state, observed only for the monosubstituted $c$-type and not for the disubstituted $d$-type. It is worth noting that this also occurs for the ortho-substituted $\mathbf{2 b}$ thiazole. 
Table 4. Bond distances $\left(d_{\mathrm{B}}\right)$ and angles involved on intermolecular hydrogen bonding in ground $\left(\mathrm{S}_{0}\right)$ and excited $\left(S_{1}\right)$ states for the enol tautomer of the studied compounds

\begin{tabular}{cccccccccc}
\hline & \multicolumn{3}{c}{$\mathrm{S}_{0}$} & \multicolumn{3}{c}{$\mathrm{S}_{1}$} & \multicolumn{3}{c}{ Difference $\mathrm{S}_{1}-\mathrm{S}_{0}$} \\
& $d_{\mathrm{B}}$ & $d_{\mathrm{B}}$ & angle & $d_{\mathrm{B}}$ & $d_{\mathrm{B}}$ & angle & $\Delta d_{\mathrm{B}}$ & $\Delta d_{\mathrm{B}}$ & $\Delta$ angle \\
& $\mathrm{O}-\mathrm{H}$ & $\mathrm{N} \cdots \mathrm{H}$ & $\mathrm{O}-\mathrm{H} \cdots \mathrm{N}$ & $\mathrm{O}-\mathrm{H}$ & $\mathrm{N} \cdots \mathrm{H}$ & $\mathrm{O}-\mathrm{H} \cdots \mathrm{N}$ & $\mathrm{O}-\mathrm{H}$ & $\mathrm{N} \cdots \mathrm{H}$ & $\mathrm{O}-\mathrm{H} \cdots \mathrm{N}$ \\
& $(\AA)$ & $(\AA)$ & $\left({ }^{\circ}\right)$ & $(\AA)$ & $(\AA)$ & $\left({ }^{\circ}\right)$ & $(\AA)$ & $(\AA)$ & $\left({ }^{\circ}\right)$ \\
\hline $\mathbf{1 a ^ { * }}$ & 0.992 & 1.711 & 148.8 & 1.009 & 1.653 & 149.7 & 0.017 & -0.058 & 0.9 \\
$\mathbf{1 b}$ & 0.995 & 1.684 & 150.6 & 1.008 & 1.639 & 151.1 & 0.013 & -0.045 & 0.5 \\
$\mathbf{1 c}$ & 0.984 & 1.841 & 146.6 & 1.032 & 1.572 & 150.9 & 0.048 & -0.269 & 4.3 \\
$\mathbf{1 d}$ & 0.988 & 1.783 & 149.0 & 1.011 & 1.578 & 152.0 & 0.023 & -0.205 & 3.0 \\
$\mathbf{2 a *}$ & 0.986 & 1.765 & 147.0 & 1.005 & 1.692 & 148.9 & 0.019 & -0.073 & 1.9 \\
2b & 0.987 & 1.755 & 149.1 & 1.006 & 1.658 & 151.0 & 0.019 & -0.097 & 1.9 \\
2c & 0.986 & 1.764 & 146.9 & 1.039 & 1.545 & 151.4 & 0.053 & -0.219 & 4.5 \\
2d & 0.985 & 1.806 & 148.1 & 1.001 & 1.629 & 151.7 & 0.016 & -0.177 & 3.6 \\
3a* & 0.989 & 1.742 & 147.9 & 1.003 & 1.678 & 149.7 & 0.014 & -0.064 & 1.8 \\
3b & 0.993 & 1.686 & 150.2 & 1.046 & 1.492 & 153.9 & 0.053 & -0.194 & 3.7 \\
3c & 0.988 & 1.736 & 147.9 & 1.042 & 1.541 & 152.1 & 0.054 & -0.195 & 4.2 \\
3d & 0.987 & 1.778 & 148.4 & 1.007 & 1.610 & 152.4 & 0.020 & -0.168 & 4.0 \\
\hline
\end{tabular}

* data have been published before ${ }^{27}$ and are reported in this work only for comparison purposes

The vibrational stretching of the $\mathrm{O}-\mathrm{H}$ mode involved in intramolecular hydrogen bonding in $-\mathrm{O}-\mathrm{H} \cdots \mathrm{N}-$ may provide evidence of the strengthening or weakening of the intramolecular hydrogen bonding in the excited state. If by comparing the stretching signal of the $\mathrm{O}-\mathrm{H}$ mode between the ground and excited states, it is found that in the excited state this stretching band has shifted to a lower energy region, the intramolecular hydrogen bond has been strengthened..$^{36-39}$ The obtained data indicate that for all the studied compounds, hydrogen bonding in the excited state has intensified (Table 5), although there is no systematic variation on vibrational frequencies according to the substitution. It should be pointed out the dramatic effect that substitution by two tert-butyl groups has over the imidazole derivative. At the ground state, $\mathbf{1} \mathbf{d}$ has a band $80 \mathrm{~cm}^{-1}$ higher energy stretching $\mathrm{O}-\mathrm{H}$ bond compared to 1 a. However, in the excited state this same stretching mode comes at an energy $610 \mathrm{~cm}^{-1}$ smaller for $1 \mathbf{d}$ than $1 \mathbf{a}$. Thus, substitution at the ortho and para positions of 1 establishes a much more intensified hydrogen bond in the excited state, favoring ESIPT, than with the other two triphenylazoles. In the context of imidazoles, maybe the effect of these substitutions could be responsible, in part, for the efficiency of $\mathrm{H}^{+}$migration even when it is coupled to an electron transfer reaction. ${ }^{12,19,27,32,40}$ However, our current data cannot be used directly in such discussion. 
Table 5. Vibrational stretching (in $\mathrm{cm}^{-1}$ ) of the $\mathrm{O}-\mathrm{H}$ mode in the ground $\left(\mathrm{S}_{0}\right)$ and excited $\left(\mathrm{S}_{1}\right)$ states for the studied compounds

\begin{tabular}{cccc}
\hline & \multicolumn{3}{c}{$v_{(\mathrm{O}-\mathrm{H})} / \mathrm{cm}^{-1}$} \\
\cline { 2 - 4 } & $\mathrm{S}_{0}$ & $\mathrm{~S}_{1}$ & $\Delta v\left(\mathrm{~S}_{1}-\mathrm{S}_{0}\right)$ \\
\hline 1a & 3230 & 2960 & 270 \\
1b & 3165 & 2770 & 395 \\
1c & 3210 & 2890 & 320 \\
1d & 3310 & 2350 & 960 \\
2a & 3350 & 3045 & 305 \\
2b & 3325 & 3250 & 75 \\
2c & 3352 & 3092 & 260 \\
2d & 3380 & 3270 & 110 \\
3a & 3290 & 3055 & 235 \\
3b & 3185 & 2970 & 215 \\
3c & 3275 & 3045 & 230 \\
3d & 3330 & 3205 & 125 \\
\hline
\end{tabular}

\section{Potential energy curves for proton transfer}

Potential energy curve plays an essential role in the photophysical study of molecular systems, being used to track the energy change along the reaction coordinate variation in the ground $\left(\mathrm{S}_{0}\right)$ and excited $\left(\mathrm{S}_{1}\right)$ states. In this study, the variation of the $\mathrm{O}-\mathrm{H}$ bond distance is used as the reaction coordinate. TD-DFT/B3LYP is considered a sufficiently reliable approach to generate qualitative potential energy curves for proton transfer reactions, although it is not expected to be sufficiently accurate to produce the correct ordering of electronic states. $^{34,41,42}$

After analyzing the potential energy curves, Figures 3-5, it can be seen that the ESIPT mechanism can be described as: (i) in the ground state, the nitrogen atom attracts the acidic hydrogen from the phenolic ring forming a strong intramolecular hydrogen bond $(-\mathrm{OH} \cdot \mathrm{N})$, which gives the molecule great stability against other possible conformations; (ii) after photoexcitation, as LUMO analysis also indicated, ESIPT reaction can occur, i.e., hydroxyl group acts as a proton donor and the azole nitrogen acts as the acid hydrogen acceptor; (iii) after the formation of the keto tautomer in the excited state, the system vibrationally relaxes, fluorescence emission occurs, and (iv) keto is converted to enol tautomer, the most stable in ground state. 


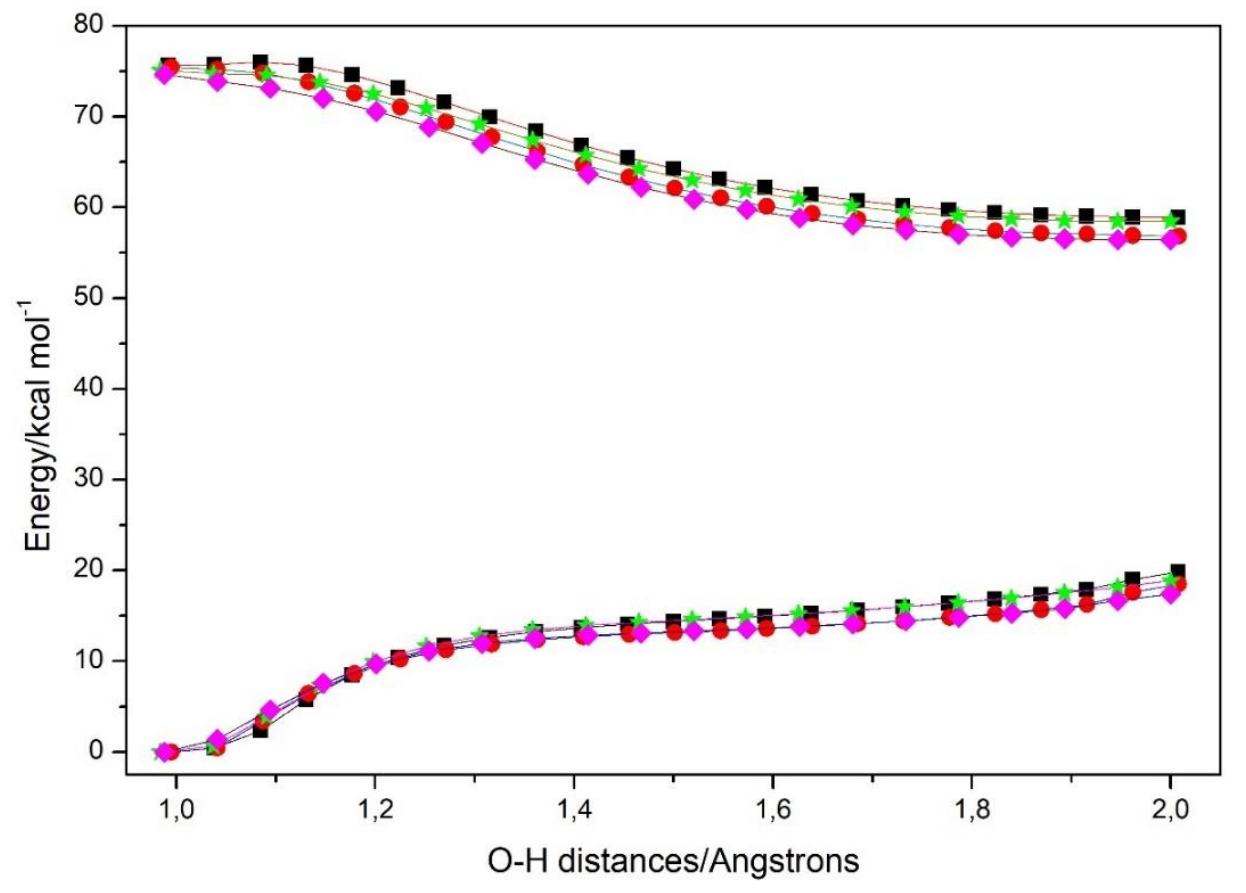

Figure 3. Potential energy curves for proton transfer calculated on ground $\left(S_{0}\right)$ and excited $\left(S_{1}\right)$ states for imidazole derivatives (1a: $\mathbf{a} ; \mathbf{1} \mathbf{b}: \bullet ; \mathbf{1 c}: \star \mathbf{1 d}$ : $\diamond$ ).

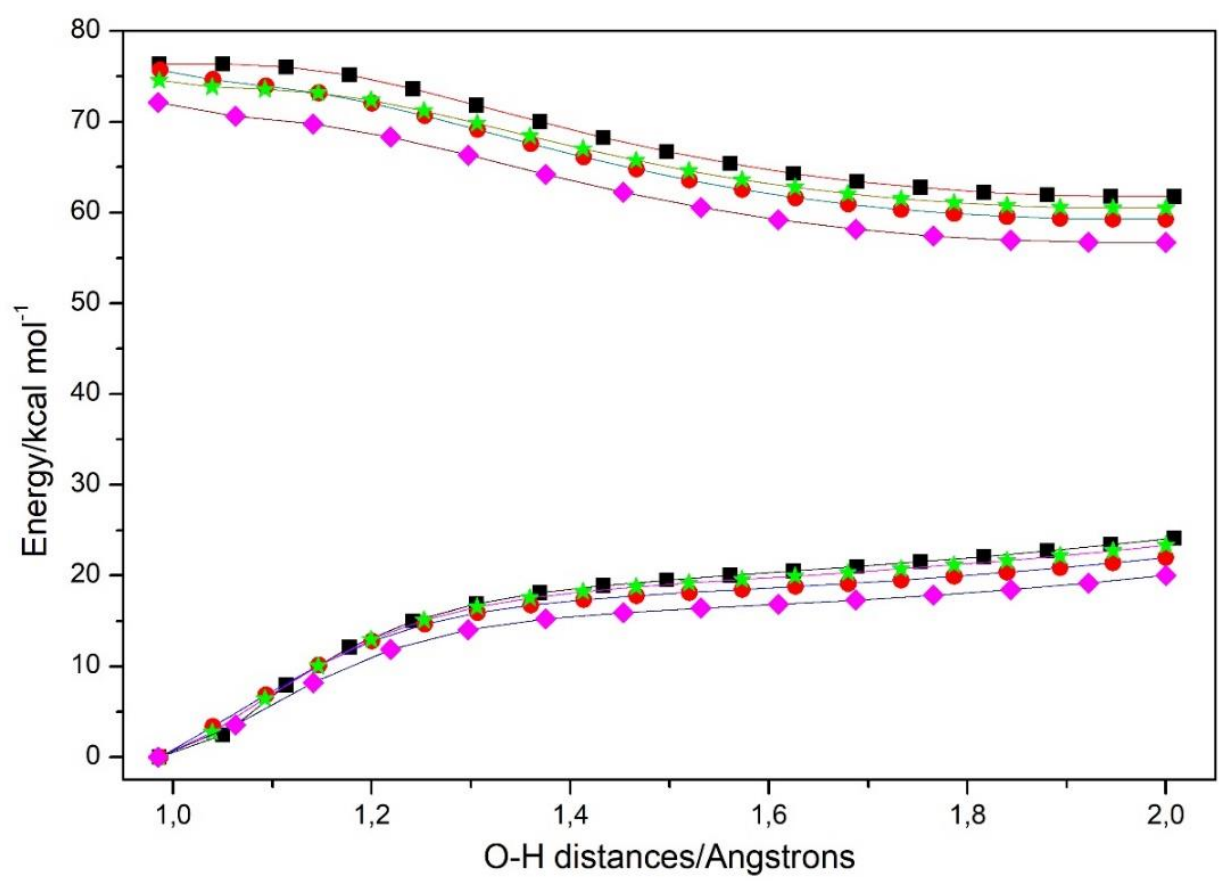

Figure 4. Potential energy curves for proton transfer calculated on ground $\left(\mathrm{S}_{0}\right)$ and excited $\left(\mathrm{S}_{1}\right)$ states for oxazole derivatives (2a: $\mathbf{\square} ; \mathbf{2} \mathbf{b}: \bullet ; \mathbf{2 c}$ : $\star ; \mathbf{2 d}: \diamond)$ ). 


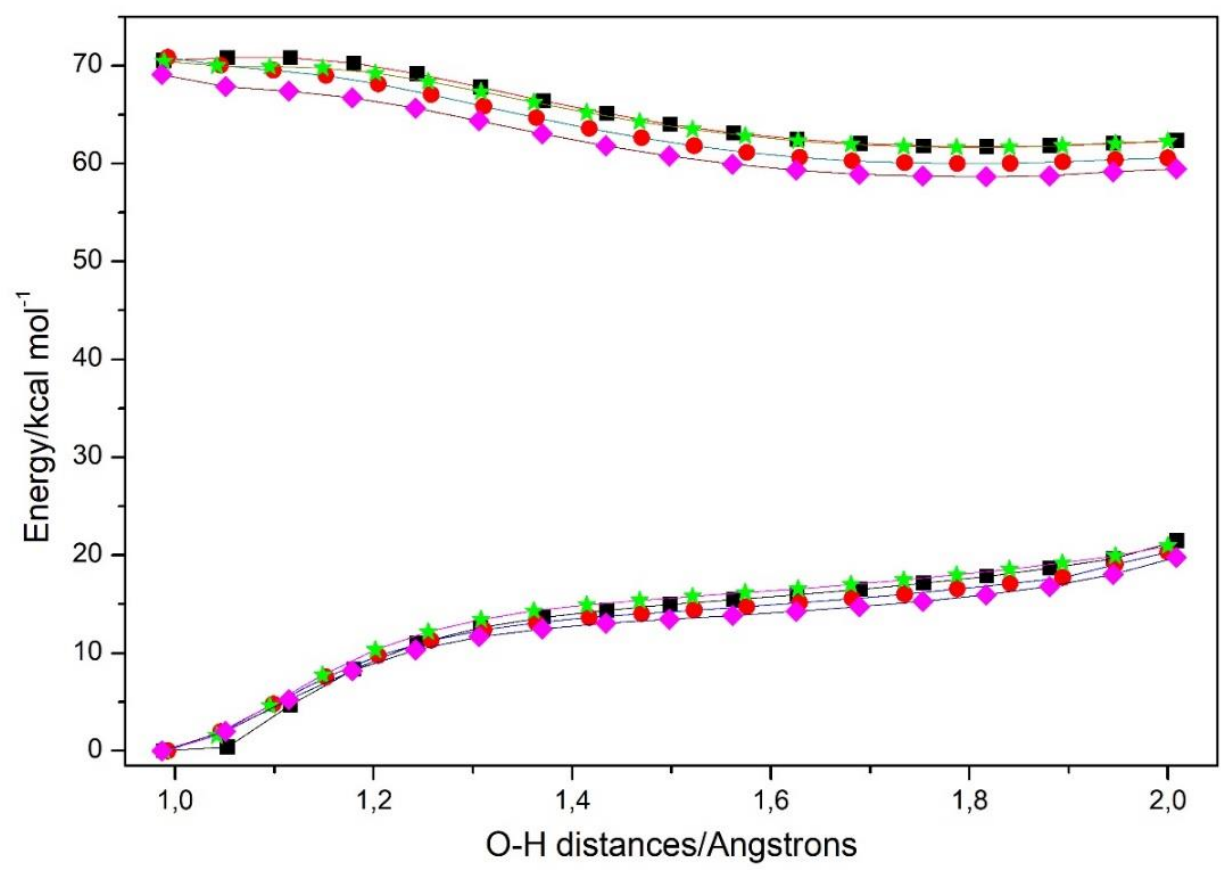

Figure 5. Potential energy curves for proton transfer calculated on ground $\left(\mathrm{S}_{0}\right)$ and excited $\left(\mathrm{S}_{1}\right)$ states for thiazole derivatives (3a: $\mathbf{a}$; 3b: $\bullet$; 3c: $\star$; $3 \mathbf{d}:>$ ).

A strong intramolecular hydrogen bond results in a closer approximation between the phenolic groups and the common azole nitrogen involved in this intramolecular interaction, lowering the energy barrier between the excited enolic and ketonic tautomers facilitating the ESIPT, as already shown elsewhere. 4,27 This trend was also observed here (Figures 3 to 5): the derivatives with the electron-donating tert-butyl groups showed the strengthening of intramolecular hydrogen bonding in the excited state, leading to the lowering of the already low proton transfer barrier. Hao and Yang ${ }^{34}$ obtained barriers around 4 to $5 \mathrm{kcal}^{\mathrm{mol}}{ }^{-1}$ for some benzoxazole derivatives; here, ESIPT for the derivatives 1-3 seem barrierless. The $\mathrm{S}_{1}$ curves for all substituted derivatives (b to $\mathbf{d}$-types) are always lower than that obtained for the non-substituted compound (a-type structures), mainly for ortho-substituted compounds ( $b$ and $d$-type). Thus, even at a small extent, substitution by the alkyl group places the excited states involved with proton transfer at smaller energies.

\section{Conclusions}

ESIPT on triphenyl-substituted heterocyclic (imidazole, oxazole and thiazole) tert-butyl derivatives have the enolic species as the most stable tautomer in the ground state $\left(\mathrm{S}_{0}\right)$ and ketonic species as the most stable in the excited state $\left(\mathrm{S}_{1}\right)$. In $\mathrm{S}_{1}$, the enol forms exhibit longer $-\mathrm{O}-\mathrm{H}$ and shorter $-\mathrm{OH} \cdots \mathrm{N}$ distances indicating stronger excited state Hydrogen bonds.

The electron-donating ability of tert-butyl on 2-phenyl, extended to the conjugated system, enhances the stability of the enol form, especially for the imidazole derivative. More evident electron donor patterns are observed for the para substituted derivatives. Ortho only substitutions favor closed conformations due to sterical clash. Interestingly, the opposite pattern is observed for the excited state when compared to ground state, where tert-butyl substitution results in smaller HOMO-LUMO energy gaps and stronger hydrogen bonds. 
The main transition in the electronic absorption spectra has strong HOMO-LUMO character. The analysis of the electronic densities at the HOMO and LUMO showed some characteristics of how these energy levels behave for the ESIPT process to occur. In HOMO, there is the participation of the phenolic oxygen atom, however in LUMO, the electron density on this atom decreases, which should favor the ESIPT. At this point, LUMO of keto tautomers, especially for imidazole derivatives, is more affected by the presence of the substituent. To complete all these observations, we have analyzed potential energy curves, which indicate that whereas in the ground state there would be an energy barrier for proton transfer from enol to keto form, in the excited state this process is nearly barrierless for tert-butyl substituted compounds. This phenomenon may have implications for other proton-migrating mechanisms involving hydroxylated triphenylazoles containing tert-butyl groups.

\section{Experimental Section}

Systems involving hydrogen bonding and proton transfer in the excited state have been successfully studied with the Density Functional Theory (DFT). In the work of Ramalho et al. ${ }^{19}$, some functionals were tested and B3LYP was the most adequate functional employed in the study of an amino-naphthoquinone derivative capable of performing ESIPT. Also, previous studies demonstrated that the functional B3LYP is very reliable for obtaining the potential energy curves in the ground and excited states (see, for example, references $4,19,49,50,24,27,43-48$ ).

So, in this work, DFT and TD-DFT were employed to obtain all the structure and electronic properties for tert-butyl derivatives of hydroxylated triphenylimidazole (1), triphenyloxazole (2), and triphenylthiazole (3), all in ground and excited states, with B3LYP functional and $6-31 \mathrm{G}(2 \mathrm{~d}, 2 \mathrm{p})$ basis set. All calculations employed the ORCA program, version 3.0.3. ${ }^{51}$ All structures presented in this work were fully optimized, so we have found closed (enol), open and rotamer conformations. To ensure these structures are in a minimum, we have performed frequency calculations. Ketone tautomers in ground state were obtained by freezing the $\mathrm{N}-\mathrm{H}$ bond length. Atomic charges derived from the electrostatic potential were calculated using ChelpG scheme. TD-DFT calculations were performed considering 40 singlet states to obtain the electronic absorption spectra, as well as, frontier molecular orbital energies to optimize the geometries in the excited state.

Potential energy curves were constructed based on scan calculations: it started using optimized enol structure and the elongation of $\mathrm{O}-\mathrm{H}$ bond distance (the selected reaction coordinate) is done within 25 steps until the formation of the keto tautomer. At each step, all the other atoms are relaxed. It should be noted, however, that the transition state was not characterized. Thus, the curves obtained from the scan are only reaction barrier estimates. At each step, the geometry of the ground state molecule was optimized and then the energies of the ground and excited state systems were calculated as a vertical transition.

\section{Acknowledgements}

Authors thank Brazilian agencies for financial support: P.H.M. thanks FAPESP (Proc. \# 17/23416-9) and CNPq (Proc. \# 448125/2014-5 and 448125/2014-5), and F.H.B. thanks FAPESP (Proc. \# 12/13807-7). This study was financed in part by the Coordenação de Aperfeiçoamento de Pessoal de Nível Superior - Brasil (CAPES) Finance Code 001. 


\section{Supplementary Material}

Atomic numbering scheme adopted along the text, optimized structures in open, closed (enol), keto and rotamer forms, bond distances and angles obtained for the studied compounds in ground $\left(\mathrm{S}_{0}\right)$ and excited $\left(\mathrm{S}_{1}\right)$ states, and molecular orbitals.

\section{References}

1. Zhao, J.; Ji, S.; Chen, Y.; Guo, H.; Yang, P. Phys. Chem. Chem. Phys. 2012, 14 (25), 8803-8817. https://doi.org/10.1039/c2cp23144a

2. Sedgwick, A. C.; Wu, L.; Han, H. H.; Bull, S. D.; He, X. P.; James, T. D.; Sessler, J. L.; Tang, B. Z.; Tian, H.; Yoon, J. Chem. Soc. Rev. 2018, 47 (23), 8842-8880.

\section{https://doi.org/10.1039/c8cs00185e}

3. Orfão, R. B.; De Carvalho, F.; Homem-De-Mello, P.; Bartoloni, F. H. J. Braz. Chem. Soc. 2017, 28 (10), 18961904.

https://doi.org/10.21577/0103-5053.20170024

4. An, B.; Yuan, H.; Zhu, Q.; Li, Y.; Guo, X.; Zhang, J. Spectrochim. Acta A 2017, 175, 36-42. https://doi.org/10.1016/i.saa.2016.12.020

5. Brito Da Silva, C.; Gil, E. S.; Da Silveira Santos, F.; Morás, A. M.; Steffens, L.; Bruno Gonçalves, P. F.; Moura, D. J.; Lüdtke, D. S.; Rodembusch, F. S. J. Org. Chem. 2018, 83 (24), 15210-15224.

https://doi.org/10.1021/acs.joc.8b02489

6. Jayabharathi, J.; Kalaiarasi, V.; Thanikachalam, V.; Jayamoorthy, K. J. Fluoresc. 2014, 24 (2), 625-637. https://doi.org/10.1007/s10895-013-1336-1

7. Deshmukh, M. S.; Sekar, N. Spectrochim. Acta A 2015, 135, 457-465. https://doi.org/10.1016/j.saa.2014.07.021

8. Alarcos, N.; Gutiérrez, M.; Liras, M.; Sánchez, F.; Moreno, M.; Douhal, A. Phys. Chem. Chem. Phys. 2015, 17 (22), 14569-14581.

https://doi.org/10.1039/c5cp01437a

9. Taki, M.; Wolford, J. L.; O’Halloran, T. V. J. Am. Chem. Soc. 2004, 126 (3), 712-713. https://doi.org/10.1021/ja039073j

10. Orfao Jr., R. B.; Alves, J.; Bartoloni, F. H. J. Fluoresc. 2016, 26 (4), 1373-1380. https://doi.org/10.1007/s10895-016-1828-x

11. Garcia, O.; Garrido, L.; Sastre, R.; Costela, A.; Garcia-Moreno, I. Adv. Funct. Mater. 2008, 18 (14), 20172025.

\section{https://doi.org/10.1002/adfm.200701395}

12. Shynkar, V. V; Klymchenko, A. S.; Piemont, E.; Demchenko, A. P.; Mely, Y. J. Phys. Chem. A 2004, 108 (40), 8151-8159.

\section{https://doi.org/10.1021/jp047990I}

13. Wu, Y.; Peng, X.; Fan, J.; Gao, S.; Tian, M.; Zhao, J.; Sun, S. J. Org. Chem. 2007, 72 (1), 62-70. https://doi.org/10.1021/jo061634c

14. Hu, R.; Feng, J.; Hu, D.; Wang, S.; Li, S.; Li, Y.; Yang, G. Angew. Chemie-International Ed. 2010, 49 (29), 4915-4918. 
15. Tang, K.-C.; Chang, M.-J.; Lin, T.-Y.; Pan, H.-A.; Fang, T.-C.; Chen, K.-Y.; Hung, W.-Y.; Hsu, Y.-H.; Chou, P.-T. J. Am. Chem. Soc. 2011, 133 (44), 17738-17745.

https://doi.org/10.1021/ja2062693

16. Hsieh, C.-C.; Jiang, C.-M.; Chou, P.-T. Acc. Chem. Res. 2010, 43 (10), 1364-1374.

https://doi.org/10.1021/ar1000499

17. Wu, J.; Liu, W.; Ge, J.; Zhang, H.; Wang, P. Chem. Soc. Rev. 2011, 40 (7), 3483-3495.

https://doi.org/10.1039/c0cs00224k

18. Houari, Y.; Chibani, S.; Jacquemin, D.; Laurent, A. D. J. Phys. Chem. B 2015, 119 (6, SI), 2180-2192. https://doi.org/10.1021/ip505036d

19. Rocha, E. P.; Ramalho, T. C. Theor. Chem. Acc. 2016, 135 (2), 1-11.

https://doi.org/10.1007/s00214-015-1786-4

20. Latha, V.; Annaraj, B.; Neelakantan, M. A. Spectrochim. Acta A 2014, 133, 44-53.

https://doi.org/10.1016/j.saa.2014.04.192

21. Roohi, H.; Mohtamedifar, N.; Hejazi, F. Chem. Phys. 2014, 444, 66-76.

https://doi.org/10.1016/j.chemphys.2014.10.006

22. Chai, S.; Cong, S.-L. Comput. Theor. Chem. 2014, 1034, 80-84.

https://doi.org/10.1016/j.comptc.2014.02.019

23. Deshmukh, M. S.; Sekar, N. Dye. Pigment. 2015, 113, 189-199.

https://doi.org/10.1016/i.dyepig.2014.08.009

24. Kataria, S.; Rhyman, L.; Ramasami, P.; Sekar, N. J. Fluoresc. 2016, 26 (5), 1805-1812.

https://doi.org/10.1007/s10895-016-1872-6

25. Purkayastha, P.; Chattopadhyay, N. Int. J. Mol. Sci. 2003, 4 (6), 335-361.

https://doi.org/10.3390/i4060335

26. Nakashima, K. Biomed. Chromatogr. 2003, 17 (2-3), 83-95.

\section{https://doi.org/10.1002/bmc.226.}

27. De Carvalho, F.; Coutinho Neto, M. D.; Bartoloni, F. H.; Homem-de-Mello, P. Molecules 2018, 23 (5), 12311245.

https://doi.org/10.3390/molecules23051231

28. Barboza, C. A.; Germino, J. C.; Santana, A. M.; Quites, F. J.; Muniz Vazquez, P. A.; Zambon Atvars, T. D. J. Phys. Chem. C. 2015, 119 (11), 6152-6163.

https://doi.org/10.1021/ip510476h

29. Markle, T. F.; Mayer, J. M. Angew. Chemie - Int. Ed. 2008, 47 (4), 738-740.

https://doi.org/10.1002/anie.200702486

30. Fecenko, C. J.; Thorp, H. H.; Meyer, T. J. J. Am. Chem. Soc. 2007, 129 (49), 15098-15099.

https://doi.org/10.1021/ja072558d

31. Phenols, H.; Rhile, I. J.; Markle, T. F.; Nagao, H.; Dipasquale, A. G.; Lam, O. P.; Lockwood, M. a; Rotter, K.; Mayer, J. M. J. Am. Chem. Soc. 2006, 128 (18), 6075-6088.

32. Dempsey, J. L.; Winkler, J. R.; Gray, H. B. J. Am. Chem. Soc. 2010, 132 (47), 16774-16776. https://doi.org/10.1021/ja109351h

33. Chipem, F. A. S.; Behera, S. K.; Krishnamoorthy, G. J. Phys. Chem. A 2013, 117 (20), 4084-4095. https://doi.org/10.1021/ip311438s

34. Hao, J.; Yang, Y. Org. Chem. Front. 2018, 5 (14), 2234-2243.

\section{https://doi.org/10.1039/c8qo00349a}

35. Zhao, G.-J.; Liu, J.-Y.; Zhou, L.-C.; Han, K.-L. J. Phys. Chem. B 2007, 111 (30), 8940-8945. 
https://doi.org/10.1021/jp0734530

36. Zhao, G.-J.; Han, K.-L. J. Phisical Chem. A 2007, 111 (13), 2469-2474.

https://doi.org/10.1021/jp068420j

37. Zhao, G.-J.; Han, K.-L. Acc. Chem. Res. 2012, 45 (3), 404-413.

https://doi.org/10.1021/ar200135h

38. Yang, Y.; Liu, Y.; Yang, D.; Li, H.; Jiang, K.; Sun, J. Spectrochim. Acta part A-Molecular Biomol. Spectrosc. 2015, 151, 814-820.

39. Scheiner, S.; Kar, T. J. Phys. Chem. A 2002, 106 (9), 1784-1789.

https://doi.org/10.1021/ip013702z

40. Jadhav, M. M.; Alswaidan, I. A.; Rhyman, L.; Ramasami, P.; Sekar, N. J. Solution Chem. 2017, 46 (5), $1005-$ 1023.

https://doi.org/10.1007/s10953-017-0628-5

41. Li, C.; Yang, Y.; Ma, C.; Liu, Y. RSC Adv. 2016, 6 (6), 5134-5140.

https://doi.org/10.1039/c5ra23261a

42. Li, C.; Yang, Y.; Li, D.; Liu, Y. Phys. Chem. Chem. Phys. 2017, 19 (6), 4802-4808.

https://doi.org/10.1039/c6cp07716a

43. Makhal, S. C.; Bhattacharyya, A.; Ghosh, S.; Guchhait, N. J. Photochem. Photobiol. A-Chemistry 2018, 358, 138-146.

https://doi.org/10.1016/j.jphotochem.2018.03.010

44. Padalkar, V. S.; Ramasami, P.; Sekar, N. J. Fluoresc. 2013, 23 (5), 839-851.

https://doi.org/10.1007/s10895-013-1201-2

45. Lan, R.-F.; Yang, Y.-F.; Ma, Y.-Z.; Li, Y.-Q. Spectrochim. Acta part A-Molecular Biomol. Spectrosc. 2017, 183, 37-44.

46. Wei, Q.; Zhou, Q.; Zhao, M.; Zhang, M.; Song, P. J. Lumin. 2017, 183, 7-12.

https://doi.org/10.1016/j.jlumin.2016.11.024

47. Hao, J.; Yang, Y. Chem. Phys. 2018, 501, 53-59.

https://doi.org/10.1016/i.chemphys.2017.11.019

48. Yang, D.; Li, P.; Zheng, R.; Wang, Y.; Lv, J. Theor. Chem. Acc. 2016, 135 (2), 1-7.

https://doi.org/10.1007/s00214-015-1802-8

49. Prommin, C.; Kanlayakan, N.; Chansen, W.; Salaeh, R.; Kerdpol, K.; Daengngern, R.; Kungwan, N. J. Phys. Chem. A 2017, 121 (31), 5773-5784.

https://doi.org/10.1021/acs.jpca.7b03454

50. Zhang, M.; Zhou, Q.; Du, C.; Ding, Y.; Song, P. RSC Adv. 2016, 6 (64), 59389-59394.

https://doi.org/10.1039/c6ra11140h

51. Neese, F. Wiley Interdiscip. Rev. Comput. Mol. Sci. 2012, 2 (1), 73-78.

https://doi.org/10.1002/wcms.81

This paper is an open access article distributed under the terms of the Creative Commons Attribution (CC BY) license (http://creativecommons.org/licenses/by/4.0/ 